\title{
Estradiol selectively regulates innate immune function by polarized human uterine epithelial cells in culture
}

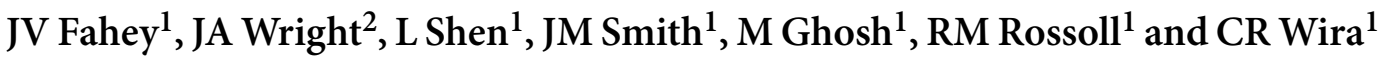

The goal of this study was to examine the role of $E_{2}$ in regulating innate immune protection by human uterine epithelial cells (UECs). Recognizing that UECs produce cytokines and chemokines to recruit and activate immune cells as well as viral and bacterial antimicrobials, we sought to examine the effect of $E_{2}$ on constitutive and Toll-like receptor (TLR) agonist (lipopolysaccharide (LPS) and poly (I:C))-induced immune responses. The secretion by polarized UECs in culture of interleukin (IL)-6, macrophage inhibitory factor (MIF), and secretory leukocyte protease inhibitor (SLPI) was examined as well as the mRNA expression of human $\beta$-defensin-2 (HBD2), tumor necrosis factor (TNF)- $\alpha$, IL-8, and nuclear factor (NF)-kB. When incubated with $E_{2}$ for $24-48 h$, we found that $E_{2}$ stimulated UEC secretion of SLPI (fourfold) and mRNA expression of HBD2 (fivefold). Moreover, when antibacterial activity in UEC secretions was measured using Staphylococcus aureus, $\mathrm{E}_{2}$ increased the secretion of soluble factor(s) with antibacterial activity. In contrast, $\mathrm{E}_{2}$ had no effect on constitutive secretion of proinflammatory cytokines and chemokines by UECs but completely inhibited LPS- and poly (I:C)-induced secretion of MIF, IL-6, and IL-8. Estradiol also reversed the stimulatory effects of IL-1 $\beta$ on mRNA expression of TNF- $\alpha$, IL-8, and NF-kB by 85,95 , and $70 \%$, respectively. As SLPI is known to inhibit NF-kB expression, these findings suggest that $\mathrm{E}_{2}$ inhibition of proinflammatory cytokines may be mediated through SLPI regulation of NF-kB. Overall, these findings indicate that the production of cytokines, chemokines, and antimicrobials by UECs are differentially regulated by $\mathrm{E}_{2}$. Further, it suggests that with $\mathrm{E}_{2}$ regulation, epithelial cells that line the uterine cavity have evolved immunologically to be sensitive to viral and bacterial infections as well as the constraints of procreation.

\section{INTRODUCTION}

Polarized epithelial cells of the female reproductive tract (FRT) are recognized as essential for reproductive health and, therefore, for survival of the species (for review, see ref. 1,2). These cells reside throughout the FRT, where they provide a physical barrier, sense and respond to potential pathogens as well as provide an environment for fetal survival and perpetuation of the species. ${ }^{3}$ The epithelial cells also discriminate between organisms to limit the growth of commensals on their external surfaces and defend underlying tissues from invading pathogens. Protection is mediated through the production of antimicrobials and the ability of epithelial cells to recruit and activate immune cells of both the innate and adaptive immune systems. ${ }^{2}$

To identify pathogens, the innate immune system uses germline encoded Toll-like receptors (TLRs), which recognize microbial antigens that are referred to as pathogen-associated molecular patterns (PAMPs). ${ }^{4}$ We have shown that TLRs are expressed on uterine epithelial cells (UECs), similar to that seen with other immune cells (lymphocytes, macrophages, dendritic cells). ${ }^{5}$ In addition to constitutive production of cytokines and chemokines (interleukin (IL)-8, IL-6, granulocyte colonystimulating factor (G-CSF), granulocyte macrophage colonystimulating factor (GM-CSF), tumor necrosis factor (TNF)- $\alpha$, and macrophage inflammatory protein- $1 \beta$ (MIP- $1 \beta),{ }^{6}$ epithelial cells from the upper FRT (uterus and Fallopian tubes) as well as FRT epithelial cell lines respond to PAMPs by enhanced production/secretion of these factors. ${ }^{5,7}$ For example, the TLR3 agonist poly (I:C) elicits the secretion of a spectrum of proinflammatory cytokines and chemokines including TNF- $\alpha$, IL-6, GM-CSF, and G-CSF, as well as the chemokines IL-8, monocyte chemotactic protein-1 (MCP-1), and MIP- $1 \beta$ that attract and activate immune cells in the FRT., ECC-1 cells, which

\footnotetext{
${ }^{1}$ Department of Physiology, Dartmouth Medical School, One Medical Center Drive, Lebanon, New Hampshire, USA . ${ }^{2}$ Present address: Department of Microbiology and Immunology, Vanderbilt University School of Medicine, Nashville TN 37232, USA. Correspondence: CR Wira (Charles R.Wira@Dartmouth.edu) 
are derived from UECs, respond to the TLR agonists zymosan and flagellin (TLR2 and -5 , respectively) by secreting increased levels of IL-8, MCP-1, and IL-6. In recent studies, we have also demonstrated that lipopolysaccharide (LPS) (TLR4) and $\mathrm{Pam}_{3}$ Cys (TLR2) treatments increase the secretion of MCP-1 and IL- 8 by UECs in culture. ${ }^{8}$

Of equal importance is the secretion of antimicrobial molecules that protect the host cells from pathogens. The functions of antimicrobial factors in host defense are multi-faceted and range from direct killing of invading microbes (bacteria, fungi, and viruses) to linking innate and acquired immunity., We and others have previously shown that epithelial cells in the FRT secrete factors that exhibit potent antimicrobial activity and include human $\alpha$-defensin-5 (HD5), $\beta$-defensins 1-4 (HBD1-4), and secretory leukocyte protease inhibitor (SLPI). ${ }^{11-13}$ These antimicrobial polypeptides, some of which are induced in response to PAMP exposure, are effective at inhibiting Gram-positive and Gram-negative bacteria, fungi, and enveloped viruses, including Neisseria gonorrhoeae, Chlamydia trachomatis, Candida albicans, Herpes Simplex Virus-2, and Human Immunodeficiency Virus-1. ${ }^{14-23}$

It is well known that estrogens, which act throughout the body, have both anti-inflammatory and proinflammatory functions. For example, $\mathrm{E}_{2}$ enhances the production of proinflammatory interferon- $\gamma$ and anti-inflammatory IL-10 in T cells. ${ }^{24}$ Direct effects of estrogen are exerted via intracellular estrogen receptors (ERs); estrogen-bound ERs up- and/or downregulate the transcription of various genes by binding to the estrogen response element of the genes or by interacting with other transcription factors. ${ }^{25,26}$ That estrogens regulate immune function in the FRT is supported by in vivo studies in which many protective functions in secretions have been found to vary with stage of the menstrual cycle. For example, HBD and SLPI in cervical secretions are cycle-dependent, with SLPI secretion highest during the secretory phase of the menstrual cycle. ${ }^{27-30}$ We and others have found that a number of cytokines, chemokines, and antimicrobials in cervical-vaginal lavage vary with stage of the menstrual cycle. ${ }^{31,32}$ Relative to that measured during the early proliferative and late secretory phases of the menstrual cycle, concentrations of SLPI, defensins, IL-8, and so on are lowest at midcycle when ovulation occurs and estradiol levels are known to be elevated. In studies with isolated polarized epithelial cells, we previously demonstrated that apical secretions from polarized human UECs from the premenopausal women, but not from postmenopausal women, were antibacterial against both Gram-positive and Gram-negative bacteria; antibacterial activity was partially neutralized with antibody to SLPI. ${ }^{11}$ These data support our working hypothesis that endocrine balance during the menstrual cycle modulates the sentinel function of epithelial cells and offers an explanation as why susceptibility to sexually transmitted pathogens varies with stage of the menstrual cycle. ${ }^{33}$

Estradiol also regulates innate immunity by suppressing the secretion and/or expression of proinflammatory mediators by epithelial cells. For example, in human keratinocytes, Kande and Watanabe ${ }^{34-36}$ demonstrated the suppression of MCP-1, regulated upon activation, normal $\mathrm{T}$-cell expressed and secreted (RANTES), and IP-10 with $\mathrm{E}_{2}$ treatment. Estradiol was also shown to suppress TLR3-induced IL-6, IL-8, and IP-10 secretion from human virally transfected endometrial cell lines. ${ }^{7}$ Previous data in the rodent from our laboratory have also shown that $\mathrm{E}_{2}$ inhibits the constitutive and TLR agonist-induced secretion of TNF- $\alpha$ and MIP- $3 \alpha .^{8}$

The goal of this study was to establish the role of $E_{2}$ in mediating UEC production of cytokines, chemokines, antimicrobials as well as direct antimicrobial activity. We found that $E_{2}$ stimulates the production of antimicrobials while at the same time inhibits the secretion and expression of PAMP-induced proinflammatory mediators by UECs. We also found increased antibacterial activity in secretions from $\mathrm{E}_{2}$-treated UECs compared to untreated controls. These data suggest a dual role of $\mathrm{E}_{2}$ in modulating immune responsiveness of UECs. On the one hand, $E_{2}$ enhances protection against pathogens by increasing antimicrobial activity. On the other, it ensures an environment for successful fertilization and pregnancy by suppressing proinflammatory responses detrimental to allogeneic sperm and a semiallogeneic fetus.

\section{RESULTS \\ Estradiol enhances secretion of the antimicrobial SLPI by ECC-1 uterine epithelial cells}

We had previously shown that SLPI is produced by primary human UECs and that SLPI in apical rinses from polarized human UECs is antibacterial against both Gram-negative and Gram-positive bacteria. ${ }^{11}$ On the basis of our findings that epithelial cells from premenopausal patients, but not from postmenopausal patients, produce SLPI we hypothesized that the secretion of SLPI would be under hormonal control. As shown in Figure 1, when polarized ECC-1 cells were incubated with $\mathrm{E}_{2}\left(5 \times 10^{-8} \mathrm{M}\right)$ for $24 \mathrm{~h}, \mathrm{E}_{2}$ enhanced the secretion of SLPI. In contrast, progesterone had no effect on SLPI secretion by the ECC- 1 cells. To more fully examine the effects of $E_{2}$ on SLPI, a dose-response study was undertaken in which epithelial cells were grown in medium alone or in the presence of increasing doses of estradiol for $24-48 \mathrm{~h}$ prior to analysis of conditioned media (CM). To ensure saturation of receptors, which occurs between $10^{-9}$ and $10^{-8} \mathrm{M}$, as well as to account for loss of free estradiol in culture owing to adherence to plastic, association with proteins in stripped FCS, and so on, estradiol was added to the incubation media at concentrations ranging from $10^{-10}$ to $10^{-7} \mathrm{M}$. In other experiments, hormone treatment with increasing concentrations of estradiol significantly increased SLPI secretion into the apical compartments.

\section{Secretions from ECC-1 cells and primary uterine epithelial cells inhibit $N$. gonorrhoeae}

We have previously shown that epithelial cell secretions inhibit the growth of Gram-negative and Gram-positive bacteria. ${ }^{11}$ To determine whether this inhibition is relevant to sexually transmitted infections, we examined the antibacterial activity of ECC-1 secretions for their ability to inhibit $N$. gonorrhoeae. As seen in Table 1, when preincubated for $1 \mathrm{~h}$ with either 
apical or basolateral secretions from polarized cells prior to plating, N. gonorrhoeae growth was significantly inhibited relative to controls. Also, shown in Table 1 is a separate experiment in which polarized UEC secretions were tested for their antibacterial activity with $N$. gonorrhoeae. Similar to our findings with ECC-1 cells, secretions from primary uterine cells inhibit $N$. gonorrhoeae growth. The information shown in Table $\mathbf{1}$ is representative of three separate experiments. Overall, these studies suggest that UECs in situ produce a spectrum of antibacterial factors that are functionally capable of inhibiting sexually transmitted pathogens.

\section{Estradiol increases bactericidal activity in secretions from ECC-1 cells}

To determine whether $\mathrm{E}_{2}$ treatment of ECC- 1 cells alters antibacterial activity, ECC-1 cells were incubated with or without $\mathrm{E}_{2}$ prior to measuring antibacterial activity in apical secretions by methods previously described. ${ }^{11}$ As shown in Figure 2, apical secretions from ECC-1 cells treated with $\mathrm{E}_{2}$ had more

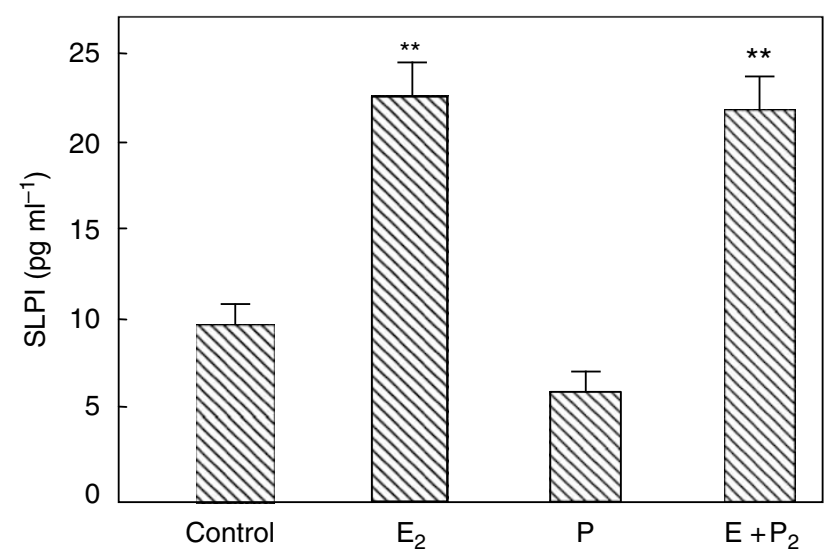

Figure 1 Estradiol increases secretory leukocyte protease inhibitor (SLPI) secretion by ECC-1 epithelial cells. Monolayer cultures of ECC-1 cells at high TER were treated with or without $5 \times 10^{-8} \mathrm{M} \mathrm{E}_{2}\left(E_{2}\right)$ or $1 \times 10^{-7} \mathrm{M}$ progesterone $(\mathrm{P})$ in the basolateral chamber of cell inserts for $24 \mathrm{~h}$. Conditioned apical media were centrifuged and supernatants were assayed for SLPI by ELISA. Four wells per group; representative of three experiments. Significantly different from control; ${ }^{*} P<0.01$. ELISA, enzyme-linked immuno sorbent assay; TER, transepithelial resistance. antibacterial activity against $S$. aureus than rinses of cells not treated with $\mathrm{E}_{2}$. As a control in these studies, $\mathrm{E}_{2}\left(1 \times 10^{-8} \mathrm{M}\right)$ was added to bacteria alone to ensure that $\mathrm{E}_{2}$ had no direct effect on bacterial viability.

\section{Estradiol enhances secretion of SLPI by polarized primary uterine epithelial cells}

We have previously shown that primary cultures of polarized UECs constitutively secrete SLPI to the apical compartment of cell inserts. ${ }^{11}$ Similar to the ECC-1 cells, primary human UECs also secrete SLPI in response to $\mathrm{E}_{2}$ (Figure 3). Primary

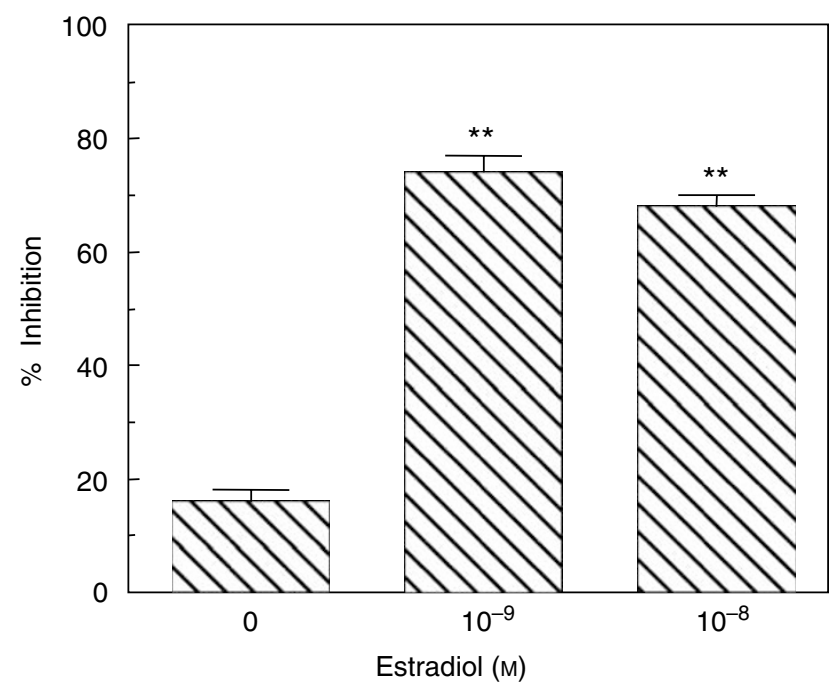

Figure 2 Estradiol enhances antibacterial activity in secretions of ECC-1 cells. Monolayer cultures of ECC-1 cells at high TER grown at air-surface interface in the apical chamber of cell inserts were treated with or without $1 \times 10^{-8}$ or $1 \times 10^{-9} \mathrm{M} \mathrm{E}_{2}$ in the basolateral chamber for $24 \mathrm{~h}$. Conditioned media (apical) were recovered as described in Methods. Following centrifugation, supernatants were incubated with Staphylococcus aureus for $1 \mathrm{~h}$, and then cultured on bacterial plates for $24 \mathrm{~h}$ and CFUs were enumerated. The mean CFUs from inserts that had been treated with media from cells without $E_{2}(0)$ and from inserts with $\mathrm{E}_{2}\left(10^{-9}\right.$ and $\left.10^{-8} \mathrm{M}\right)$ were compared with bacteria grown without conditioned media to determine percentage of inhibition. The mean inhibition \pm s.e.m. is shown. Four wells per group; representative of five experiments. Significantly different from no $E_{2} ;{ }^{* \star} P<0.01$. CFUs, colony-forming units; TER, transepithelial resistance.

Table 1 Inhibitory effect of conditioned media from uterine epithelial cells on Neisseria gonorrhoeae growth

\begin{tabular}{|c|c|c|c|c|c|c|}
\hline \multicolumn{2}{|c|}{ ECC -1 cells } & \multicolumn{3}{|c|}{ CFU counts $\left(\times 10^{3}\right)$} & $\frac{\text { Mean } \pm \text { s.e.m. }}{51 \pm 4.8}$ & $\frac{P \text {-value }}{-}$ \\
\hline Apical & 11 & 18 & 29 & 32 & $22 \pm 4.8$ & $P=0.01$ \\
\hline \multicolumn{2}{|c|}{ Primary uterine cells } & \multicolumn{3}{|c|}{ CFU counts $\left(\times 10^{5}\right)$} & Mean \pm s.e.m. & $P$-value \\
\hline Basal & 23 & 33 & 21 & 30 & $27 \pm 2$ & $P=0.001$ \\
\hline
\end{tabular}




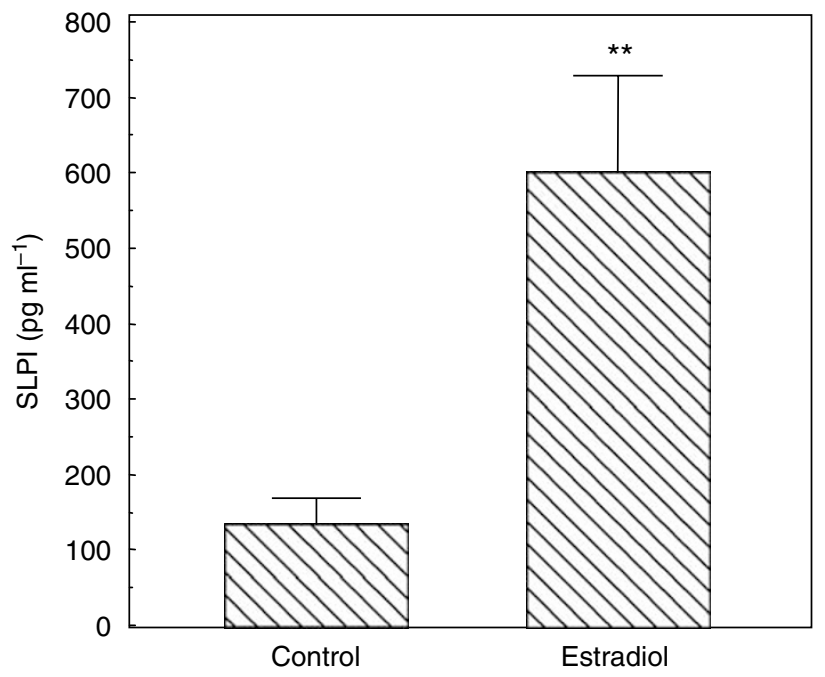

Figure 3 Estradiol increases SLPI secretion by primary UECs. Monolayer cultures of primary human UECs at high TER were treated with or without $5 \times 10^{-8} \mathrm{M} \mathrm{E}_{2}$ in the basolateral chamber of cell inserts for $24 \mathrm{~h}$. Conditioned apical media were centrifuged and supernatants were assayed for SLPI by ELISA. Four wells per group; representative of three experiments. Significantly different from control; ${ }^{* \star} P<0.01$. ELISA, enzyme-linked immuno sorbent assay; SLPI, secretory leukocyte protease inhibitor; TER, transepithelial resistance; UECs, uterine epithelial cells.

UECs secrete more SLPI than the ECC- 1 cell line (compare Figures 1 and 3). There is a direct correlation between SLPI and antibacterial activity. Estradiol increases both SLPI and antibacterial activity in the polarized UECs. We have previously demonstrated that treatment of constitutive secretions with antiSLPI neutralizes the antibacterial activity in uterine epithelial secretions. ${ }^{11}$ These data extend the association between SLPI and antibacterial activity to $\mathrm{E}_{2}$ influence. To determine whether the effect of $\mathrm{E}_{2}$ on UEC SLPI secretion is receptor-mediated, confluent epithelial cells were incubated with $\mathrm{E}_{2}$ and/or ICI 182,780 , a pure antagonist that binds the ERs. ${ }^{37}$ Epithelial cells were incubated in the presence of ICI $182,780\left(10^{-6} \mathrm{M}\right)$ alone, $\mathrm{E}_{2}\left(10^{-8} \mathrm{M}\right)$ alone, and ICI $182,780+\mathrm{E}_{2}$, for $48 \mathrm{~h}$ prior to the measurement of SLPI. We found that the presence of ICI 182,780 added just prior to $\mathrm{E}_{2}$ in two separate experiments reversed by $60-80 \%$ the stimulatory effect of $E_{2}$ on SLPI production.

\section{Estradiol increases HBD2 mRNA expression}

We have previously shown that $\mathrm{E}_{2}$ increases HBD1 and HBD2 mRNA expression in ECC- 1 cells. ${ }^{38}$ To more fully define this response in primary polarized UECs, we incubated cells with $\mathrm{E}_{2}$ for $48 \mathrm{~h}$ prior to isolating RNA and analyzing $\mathrm{HBD} 2 \mathrm{mRNA}$ by real-time reverse-transcriptase PCR (RT-PCR). As shown in Figure 4, $\mathrm{E}_{2}$ added to the culture media increased the expression of HBD2 by 5.5 -fold relative to controls.

\section{Estradiol inhibits primary uterine epithelial cell cytokine responses to TLR agonists}

Previously, we found that TLRs are expressed by primary UECs and that TLR agonists induce cytokine secretion by these cells. ${ }^{5,39}$

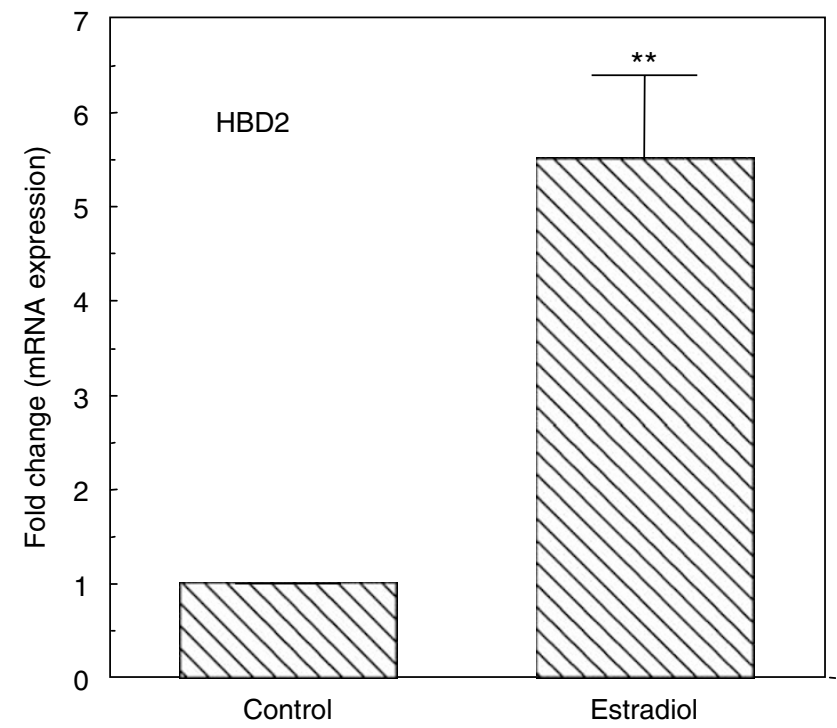

Figure 4 Estradiol enhances HBD2 mRNA expression. Primary UECs at maximal TER were treated with or without $5 \times 10^{-8} \mathrm{M} \mathrm{E}_{2}$ for $48 \mathrm{~h}$. Cellular RNA was processed as described in Methods and Taqman RT-PCR was performed using a primer probe for HBD2. Data shown are the mean \pm S.e.m. from three experiments. Significantly different from control; ${ }^{* \star} P<0.01$. HBD2, human $\beta$-defensin-2; RT-PCR, reverse-transcriptase PCR; TER, transepithelial resistance; UECs, uterine epithelial cells.

To determine if $\mathrm{E}_{2}$ regulates the secretion of the cytokines, we evaluated the effect of $\mathrm{E}_{2}$ on macrophage migration inhibitory factor (MIF) secretion by primary UECs. Cells were incubated with or without $\mathrm{E}_{2}$ in the basolateral compartment for $24 \mathrm{~h}$ after which TLR agonists LPS $\left(1 \mu \mathrm{g} \mathrm{ml}^{-1}\right)$ or poly (I:C) $\left(25 \mu \mathrm{g} \mathrm{ml}^{-1}\right)$ were added to the apical compartment for another $24 \mathrm{~h}$. The total time for $\mathrm{E}_{2}$ treatment was $48 \mathrm{~h}$. The $\mathrm{CM}$ from apical and basolateral chambers were removed and MIF was measured by enzyme-linked immuno sorbent assay (ELISA). As shown in Figure 5, LPS and poly (I:C) significantly enhanced MIF secretion into the apical compartment. Pretreatment with $\mathrm{E}_{2}$, however, effectively eliminated the responses to the TLR agonists. Similar results were found in the basolateral compartment (not shown). To more fully determine the extent to which $\mathrm{E}_{2}$ affects cytokine secretion, a separate study was carried out in which the effect of a 24-h $\mathrm{E}_{2}$ pretreatment on 24-h LPS-induced apical secretion of IL-6 was determined. As seen in Figure 6, $\mathrm{E}_{2}$ pretreatment effectively blocked the stimulatory effect of LPS on the secretion of IL-6, similar to that seen when MIF was measured under comparable conditions (Figure 5). To examine whether the effect of $\mathrm{E}_{2}\left(5 \times 10^{-8} \mathrm{M}\right)$ on UEC MIF secretion is receptor-mediated, epithelial cells were incubated with $\mathrm{E}_{2}$ and/or ICI $182,780\left(5 \times 10^{-6} \mathrm{M}\right)$. In all cases, ICI 182,780 reversed the inhibitory effects of $\mathrm{E}_{2}$ by more than $50 \%$.

\section{Estradiol inhibits constitutive and IL-1 $\beta$-induced mRNA expression of proinflammatory mediators}

To determine the extent to which $\mathrm{E}_{2}$ regulates constitutive and IL- $1 \beta$-induced expression of proinflammatory mediators, primary UECs were incubated in the presence or absence of 


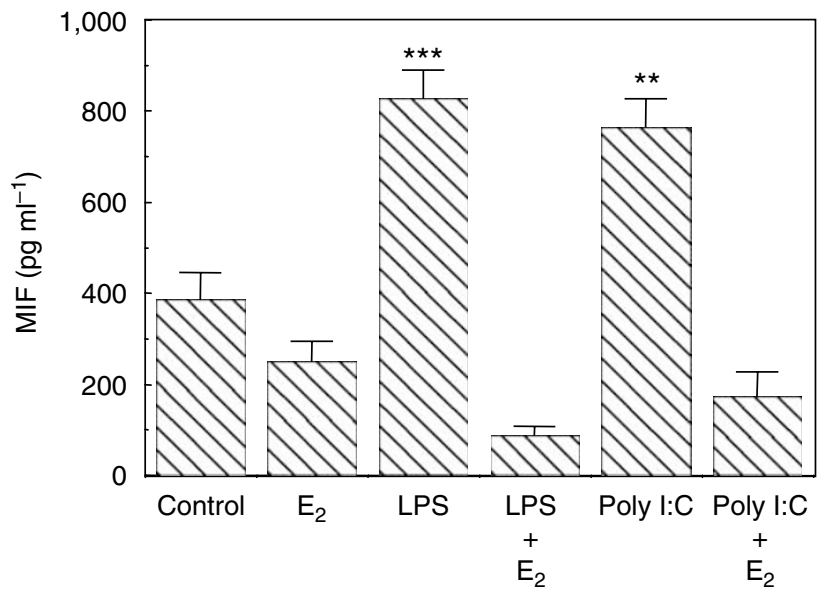

Figure 5 Estradiol inhibits TLR agonist-induced migration inhibitory factor (MIF) secretion of human primary UECs. Monolayer cultures of UECs at high TER were treated with or without $5 \times 10^{-8} \mathrm{M} \mathrm{E}_{2}$ in the basolateral chamber of cell inserts for $24 \mathrm{~h}$, then with either LPS or poly (I:C) added apically for an additional $24 \mathrm{~h}$. Conditioned apical media were centrifuged and supernatants were assayed for MIF by ELISA. Four wells per group; representative of four experiments. Significantly different from control; ${ }^{\star \star \star} P<0.001 ;{ }^{* \star} P<0.01$. ELISA, enzyme-linked immuno sorbent assay; LPS, lipopolysaccharide; TER, transepithelial resistance; TLR, Toll-like receptor; UECs, uterine epithelial cells.

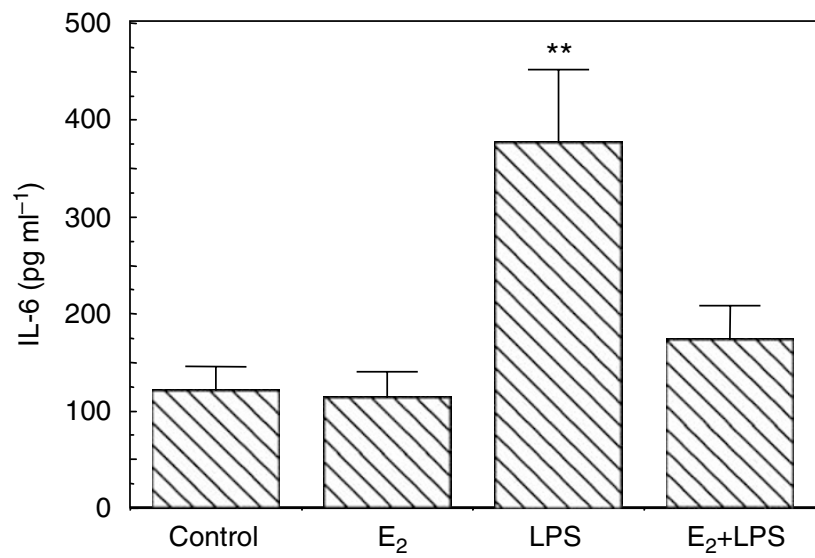

Figure 6 Estradiol inhibits LPS-induced IL-6 secretion. Monolayer cultures of UECs at high TER were treated with or without $5 \times 10^{-8} \mathrm{M} \mathrm{E}_{2}$ in the basolateral chamber of cell inserts for $24 \mathrm{~h}$, then with LPS added apically for an additional $24 \mathrm{~h}$. Conditioned apical media were centrifuged and supernatants were assayed for IL- 6 by ELISA. Four wells per group; representative of three experiments. Significantly different from control: LPS vs. E2+LPS, $P<0.05$; **LPS vs. control and LPS vs. E2, $P<0.01$. ELISA, enzyme-linked immuno sorbent assay; IL, interleukin; LPS, lipopolysaccharide; TER, transepithelial resistance; UECs, uterine epithelial cells.

$\mathrm{E}_{2}$ for $24 \mathrm{~h}$ prior to the isolation and analysis of mRNA. As seen in Figure 7, $\mathrm{E}_{2}$ reduced the constitutive mRNA expression of nuclear factor (NF)-kB by more than threefold. Recognizing that IL- $1 \beta$ is a pleiotropic cytokine that mediates inflammation, both locally and systemically, ${ }^{40}$ we determined if $\mathrm{E}_{2}$ modulates IL-1 $\beta$ responses of primary human UECs. Messenger RNA expression of proinflammatory factors was evaluated in cells incubated with or without $\mathrm{E}_{2}$ for $24 \mathrm{~h}$, and then with or without IL- $1 \beta$ for an

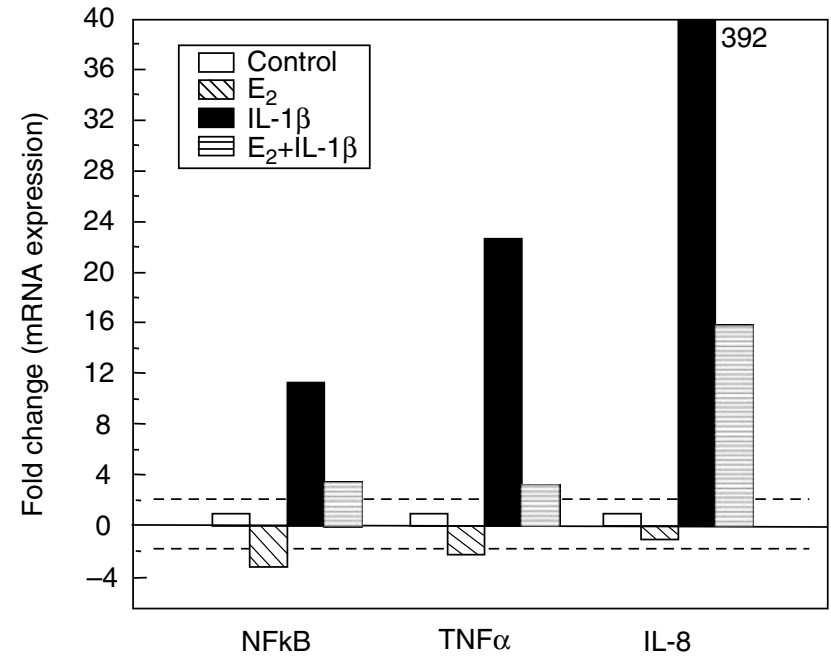

Figure 7 Estradiol inhibits IL-1 $\beta$-induced responses. Primary UECs at maximal TER were treated with or without $5 \times 10^{-8} \mathrm{M} \mathrm{E}_{2}$ for $24 \mathrm{~h}$, after which some were also treated with IL-1 $\beta$ for an additional $24 \mathrm{~h}$. Cellular RNA was processed as described in Methods and Taqman RT-PCR using primer probes for NF-kB, TNF- $\alpha$, and IL- 8 was performed. IL-1 $\beta$ increases mRNA expression of NF-kB, TNF- $\alpha$, and IL- 8 by 11.6-, 22-, and 392-fold, respectively. Pretreatment with $\mathrm{E}_{2}$ reduced these responses to IL-1 $\beta$. This experiment is representative of three separate experiments. IL, interleukin; NF-kB, nuclear factor-kB; RT-PCR, reverse-transcriptase PCR; TER, transepithelial resistance; TNF- $\alpha$, tumor necrosis factor- $\alpha$; UECs, uterine epithelial cells.

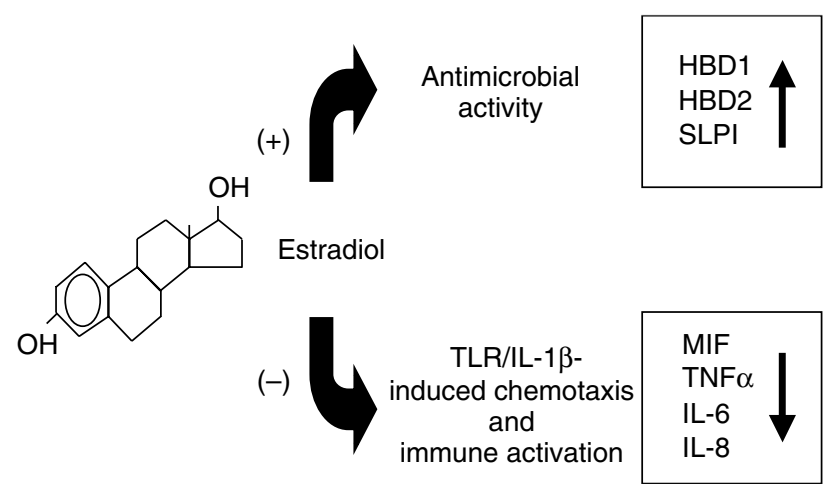

Figure 8 Schematic of integrated $E_{2}$ regulation of innate immune function by human UECs. $E_{2}$ enhances the production of peptides with antimicrobial activity and reduces the production of proinflammatory factors induced by TLR agonists and IL-1 $\beta$. IL, interleukin; TLR, Toll-like receptor; UECs, uterine epithelial cells.

additional $24 \mathrm{~h}$. As shown in Figure 7, IL-1 $\beta$ induced increases in mRNA expression of NF-kB, TNF- $\alpha$, and IL-8. Pretreatment with $\mathrm{E}_{2}$ greatly reduced these IL- $1 \beta$-induced responses.

\section{DISCUSSION}

The research presented demonstrates that UECs function at multiple levels to confer protection in the FRT. Further, these studies indicate that polarized UECs are hormonally responsive to physiological concentrations of $\mathrm{E}_{2}$ added to the culture media. Unexpectedly, we found that responses to $\mathrm{E}_{2}$ are complex and dependent on the immunological parameter measured. As summarized in Figure 8, $\mathrm{E}_{2}$ stimulates the synthesis and 
secretion of antimicrobials by polarized UECs whereas at the same time inhibits the PAMP- and IL- $1 \beta$-induced secretion of proinflammatory cytokines and chemokines. These findings suggest a key role for $\mathrm{E}_{2}$ in regulating a complex network of immune events that is mediated by UECs, the sentinels of the FRT.

Previously, we reported that polarized primary UECs in culture constitutively secrete a spectrum of cytokines, chemokines, and antimicrobials both apically and basolaterally. ${ }^{6} \mathrm{We}$ also observed that under a variety of stimuli including TLR agonists (LPS, poly (I:C)) and IL-1 $\beta$, epithelial cell secretion of cytokines, chemokines, and antimicrobials is enhanced. $5,38,39,41$ Recognizing that the functions of $\mathrm{E}_{2}$ in the FRT are multifaceted, we hypothesized that the $\mathrm{E}_{2}$ would regulate UEC immune function in a way that would allow them to act as sentinels in the FRT by protecting against potential pathogens while simultaneously providing an environment for successful fertilization, implantation, and pregnancy. To the best of our knowledge, the results presented represent the first comprehensive study that systematically examines the seemingly opposite inductive and suppressive activities of $E_{2}$ on epithelial cells from the upper FRT.

Our findings that constitutive secretion and mRNA expression of antimicrobials such as SLPI and HBD2 are increased when epithelial cells are incubated with $\mathrm{E}_{2}$ suggest that $\mathrm{E}_{2}$, produced during the menstrual cycle, acts in the uterus to prepare the tract for implantation. That this protection is broad spectrum is suggested from our previous findings that co-culture of UEC secretions with Gram-negative and Grampositive bacteria results in an SLPI-dependent inhibition of bacterial growth. ${ }^{11}$ Studies have implicated SLPI and other antimicrobials in uterine secretions with the inhibition of human immuno deficiency virus infection. ${ }^{19,42}$ To determine whether $\mathrm{E}_{2}$ treatment of polarized UECs translates into enhanced antimicrobial activity, we compared these secretions from ECC-1 cells with those from cells incubated without hormone and found that $\mathrm{E}_{2}$ enhanced antibacterial activity in secretions beyond that seen with control cells. Our finding of enhanced antibacterial activity with $\mathrm{E}_{2}$ helps to clarify an observation made by us several years ago. ${ }^{11}$ When epithelial cell secretions from the uteri of premenopausal women (proliferative and secretory phase) were compared with those from postmenopausal women, we discovered that antibacterial activity and SLPI were absent in secretions from the epithelial cells of postmenopausal women. ${ }^{11}$ Our finding that $\mathrm{E}_{2}$ increases both antibacterial activity and SLPI secretion suggests that the absence of estrogens during menopause is the underlying mechanism that accounts for the loss of SLPI-dependent immune protection by UECs. Consistent with this conclusion are the findings of Shimoya et al. ${ }^{43}$, who showed that treatment of postmenopausal women with vaginal estrogen increased the concentrations of SLPI in cervicovaginal secretions.

Our findings that UECs produce antimicrobials and that production increases in response to $\mathrm{E}_{2}$ take on a new importance with the recognition that the uterine lumen is not a sterile environment, but rather a site to which bacteria and viruses move continuously from vagina to uterus to Fallopian tubes throughout the menstrual cycle. This conclusion is based in part on studies showing that sperm deposited in the vagina reaches the Fallopian tubes within minutes. ${ }^{44}$ In other studies, demonstrated that radio-opaque dye is seen in the uterine lumen within $2 \mathrm{~h}$ of being placed in the vagina. ${ }^{45}$ Dye traveled from vagina to uterus irrespective of stage of the menstrual cycle, the use of oral contraceptives, or whether women were pre- or postmenopausal. These studies suggest that $\mathrm{E}_{2}$-induced modulation of SLPI and other antimicrobials might contribute to the relatively low infection rate per coital act of Human Immunodeficiency Virus infection and to the low number of viable bacteria recovered from secretions of the upper FRT. Further, these studies suggest that, as a part of the innate immune system, epithelial cells have the capacity to respond to hormonal changes to enhance protection at the uterine surface. That uterine hormone-induced protection is crucial to reproductive health is further supported by the findings at midcycle, when $\mathrm{E}_{2}$ levels are elevated, that cervical-vaginal concentrations of antimicrobials as well as cytokines/chemokines decline by 10 - to 100 -fold..$^{31}$ In addition to preparing the upper FRT for implantation, our findings of enhanced antimicrobial production in the uterus further suggest that midcycle secretions from the Fallopian tubes and uterus, by draining into the cervix and vagina, provide innate protection to the lower FRT when local immune protection is suppressed.

What was unexpected in our study was the finding that $\mathrm{E}_{2}$ inhibits the secretion of proinflammatory mediators by TLR agonist-stimulated UECs. Although $\mathrm{E}_{2}$ had little or no effect on constitutive secretion of proinflammatory cytokines and chemokines by UECs, it markedly inhibited LPS- and poly (I:C)-induced secretion of MIF, IL-6, and IL-8. One explanation for this inhibition is that sustained production of proinflammatory mediators may be detrimental to reproduction. For example, an overabundance of these mediators, perhaps in response to infection, may result in an inflammatory immune response that destroys sperm, trophoblast, or developing fetus. If proinflammatory responses were not dampened by $\mathrm{E}_{2}$ at the time of ovulation, then obligate semen responses might be compromised and thereby lead to infertility. Further studies are needed to define the delicate balance that exists between protection and successful implantation.

As a part of these studies, we found that $\mathrm{E}_{2}$ reversed the stimulatory effects of IL- $1 \beta$ on mRNA expression of TNF- $\alpha$, IL-8, and NF-kB. Using the ECC-1 cell line derived from the uterus, we previously showed that IL- $1 \beta$ stimulates mRNA expression and production of HBD2 and IL-8, and that these increases are suppressed by $\mathrm{E}_{2} \cdot{ }^{41} \mathrm{We}$ found that $\mathrm{E}_{2}$ inhibited the expression of IL-1Receptor type I on the ECC-1 epithelial cells. ${ }^{41}$ The present studies extend these findings to primary UECs and suggest that $\mathrm{E}_{2}$ acts by inhibiting IL-1Receptor type I so that cells respond relatively poorly to the IL-1 $\beta$ ligand. Studies are under way to determine whether a similar mechanism exists in primary UECs.

An intriguing finding in our study was the observation that $\mathrm{E}_{2}$ both stimulated SLPI production and inhibited NF-kB 
expression. The recognition by others that SLPI inhibits NF-kB expression raises the possibility that $\mathrm{E}_{2}$ inhibition of proinflammatory cytokines may be mediated through SLPI regulation of NF-kB. Lentsch, Ward, and co-workers ${ }^{46-48}$ demonstrated that SLPI inhibits inflammation in the lung and liver by blocking NF-kB activation by interfering with the breakdown of IkB $\beta$, an inhibitor of NF-kB activity. In other studies, SLPI-deficient mice were reported to be more sensitive to LPS-induced shock; their macrophages had higher IL- 6 and NF-kB activity, suggesting that SLPI attenuates excessive inflammatory responses. ${ }^{49}$ Taggart, Greene, and co-workers ${ }^{50,51}$ demonstrated that SLPI downregulates TNF- $\alpha$ expression induced by LPS by inhibiting degradation of IkB $\beta$ and binds directly to NF-kB in a sitespecific manner. More recently, $\mathrm{E}_{2}$ was found to protect against Human Immunodeficiency Virus Tat protein-induced inflammatory reactions in vascular endothelium by blocking NF-kB signaling. ${ }^{52}$ Our findings that $\mathrm{E}_{2}$ increases SLPI mRNA expression within $2 \mathrm{~h}$ (M. Ghosh et al., unpublished observation) and SLPI secretion by UECs within $24 \mathrm{~h}$ while inhibiting NF-kB mRNA expression suggest a mechanism whereby $\mathrm{E}_{2}$ functions to decrease proinflammatory cytokine and chemokine production.

The complexities of endocrine regulation observed in these studies indicate that $\mathrm{E}_{2}$ acts directly on UECs to control cytokine, chemokine, and antimicrobial production. Others have demonstrated that UECs express $E_{2}$ receptors (ERs) $\alpha$ and $\beta$ to regulate uterine function during the reproductive cycle and pregnancy (for review, see ref. 53). Rather than affecting a limited number of genes, recent studies have demonstrated that when labeled cRNAs derived from uterine tissues were hybridized with U95Av2 GeneChips (Affymetrix, Santa Clara, CA), $E_{2}$ significantly activated or repressed, by at least 1.74-fold, a total of 228 genes. ${ }^{54}$ Most genes regulated in ER- $\alpha$ cells were distinct from those regulated in ER- $\beta$ cells. The extent to which $\mathrm{E}_{2}$ exerts its effects on immunological parameters remains to be determined. Our finding that the effects of $E_{2}$ on SLPI are blocked when UECs are pretreated with ICI 182,780 , a pure antagonist that binds the ERs, suggests that the effects observed are mediated through ERs. What remains to be determined is whether the immunological effects observed are through ER- $\alpha$ and/or $-\beta$.

In conclusion, our studies indicate that $\mathrm{E}_{2}$ markedly influences innate immune protection by epithelial cells in the uterus. Epithelial cells protect in multiple ways by secreting antimicrobials and producing cytokines and chemokines to recruit and activate other immune cells when needed. The present study demonstrates that $\mathrm{E}_{2}$ is able to regulate these events in a way that is consistent with maternal protection and procreation. Given the ability of UECs to respond to potential pathogens, our findings suggest that epithelial cells are in the unique position of acting as sentinels that play a key role in immune surveillance as part of the innate and adaptive immune systems.

\section{METHODS}

TLR agonists and sex hormones. Poly (I:C) and Ultra pure LPS from Escherichia coli were obtained from InvivoGen (San Diego, CA). Estradiol-17 $\beta$ (Calbiochem, La Jolla, CA), progesterone (Calbiochem), and ICI 182,780 (Tocris, Ellisville, MO) were dissolved in 100\% ethanol, evaporated to dryness, and resuspended in media (see below). For control medium, an equivalent amount of ethanol was initially evaporated.

Primary human uterine epithelial cell isolation and culture. Uterine mucosal tissue was obtained following surgery from women who had undergone hysterectomies at Dartmouth-Hitchcock Medical Center. Tissues used in this study were distal to the sites of pathology and were determined to be unaffected by disease upon inspection by a trained pathologist. Pathologists also determined the menstrual status, as well as the stage in the cycle of premenopausal patients. Tissues were transported from Pathology and procedures to prepare purified epithelial sheets began within $2 \mathrm{~h}$ of surgery. Approval to use tissues was previously obtained from the Institutional Review-Board.

Epithelial cells were isolated as previously described. ${ }^{11,38}$ Briefly, tissues were minced under sterile conditions into 1- to 2-mm fragments and subjected to enzymatic digestion using a "PHC" enzyme mixture that contained final concentrations of $3.4 \mu \mathrm{g} \mathrm{ml}^{-1}$ pancreatin (Invitrogen, Grand Island, NY), $0.1 \mu \mathrm{g} \mathrm{ml}^{-1}$ hyaluronidase (Worthington Biochemical Corporation, Freehold, NJ), $1.6 \mu \mathrm{g} \mathrm{ml}^{-1}$ collagenase (Worthington), and $2 \mu \mathrm{g} \mathrm{ml}^{-1} \mathrm{D}$-glucose in $1 \times$ Hanks' balanced salt solution (HBSS; Invitrogen). Enzymes were chosen to maximize digestion of the extracellular matrix while minimizing digestion of cell-surface antigens. After incubating in PHC-HBSS for $1 \mathrm{~h}$ at $37^{\circ} \mathrm{C}$, cells were dispersed through a $250-\mu \mathrm{m}$ mesh screen, washed, and resuspended in Dulbecco's modified Eagle's medium/F12 complete medium with $10 \%$ fetal bovine serum (FBS). Epithelial cell sheets were separated from stromal cells by filtration through a $40-\mu \mathrm{m}$ nylon mesh filter (Small Parts, Miami Lakes, FL). Epithelial sheets were retained on the filters, while stromal cells passed through the filters. Washing and back-washing the filters with complete medium recovered epithelial sheets. Epithelial sheets were collected, centrifuged at $500 \mathrm{~g}$ for $5 \mathrm{~min}$, and resuspended in a small volume of complete medium. Using this procedure, we have isolated purified epithelial cells that stain positive for the epithelial antigens Ber-EP4 and cytokeratin and negative for CD45 and vimentin. ${ }^{55,56}$ Human UECs were seeded into the apical compartment of human extracellular matrix (BD Biosciences, Bedford, MA)-coated Falcon cell culture inserts in 24-well culture dishes designed for these cell inserts (Fisher Scientific, Pittsburgh, PA) in media and volumes as described above for the ECC1 cells. Primary UECs grew to monolayers within 3-8 days and, as an indicator of tight junction formation, transepithelial resistance (TER) was periodically assessed using an EVOM electrode and Voltohmmeter (World Precision Instruments, Sarasota, FL), as described previously. ${ }^{57}$ All primary cultures had at least fourfold values for TER compared to cell inserts without cells at the time when experiments were performed.

ECC-1 cell culture. To establish a cell culture system of polarized human UECs with both apical and basolateral compartments, the human UEC line ECC-1 (originally established by Dr Pondichery Satyaswaroop and kindly provided by George Olt, Penn State College of Medicine, Milton S Hershey Medical Center, PA) was cultured in Falcon cell culture inserts in 24-well culture dishes designed for these cell inserts (Fisher Scientific). ECC-1 cell line is a well-differentiated human UEC line with sex hormone receptors. ${ }^{58}$ For these experiments, apical and basolateral compartments had 300 and $850 \mu \mathrm{l}$ of complete medium, respectively. Complete medium was Dulbecco's modified Eagle's medium/F12 supplemented with $20 \mu \mathrm{M}$ 4-(2-hydroxyethyl)-1-piperazineethanesulfonic acid, $2 \mu \mathrm{M} \mathrm{L}$-glutamine (all from Invitrogen), $100 \mu \mathrm{g} \mathrm{ml}^{-1}$ primocin (InvivoGen), and $10 \%$ heat-inactivated FBS or $10 \%$ heat-inactivated charcoal/dextran-treated Stripped FBS (Hyclone, Logan, UT) and did not contain phenol red. In all studies using sex hormones, the FBS supplement was stripped to remove endogenous estrogens. The medium was changed every 2 days.

Measurement of IL-6, MIF, and SLPI in epithelial cell secretions. Conditioned media were recovered from the apical and basolateral compartments of cell inserts after 24 or $48 \mathrm{~h}$, centrifuged at $10,000 \mathrm{~g}$ in a 
microfuge, and the supernatants were stored at $-80^{\circ} \mathrm{C}$ until assay for concentrations of MIF, IL-6, or SLPI with ELISA test kits from R\&D Systems (Minneapolis, MN) according to the manufacturer's protocol. Standards for each ELISA were resuspended in cell culture medium. Amounts of cytokines were quantified based on a standard curve after OD measurements at $450 \mathrm{~nm}$ on an ELISA reader (Dynex, Chantilly, VA).

Taqman real-time RT-PCR. Real-time RT-PCR was done with a two-step protocol as described previously. ${ }^{5,59}$ Total RNA was isolated from cells using TRIzol Reagent according to the manufacturer's recommendations (Invitrogen Life Technologies) and purified with RNeasy columns (Qiagen, Valencia, CA). Coincident with RNA purification was oncolumn DNase digestion using the RNase-Free DNase set (Qiagen). For each specimen, $400 \mathrm{ng}$ of total RNA was reverse-transcribed using the iScript cDNA synthesis kit according to the manufacturer's recommendations (Bio-Rad, Hercules, CA) in a $20 \mu \mathrm{l}$ volume. Relative mRNA expression levels of genes of interest were measured using the $5^{\prime}$-fluorogenic nuclease assay in real-time quantitative PCR using Taqman chemistry on the ABI 7300 Prism real-time PCR instrument (Applied Biosystems, Foster City, CA). The HBD2, NF-kB, TNF- $\alpha$, IL- 8 , and $\beta$-actin primer/ MGB probe sets were obtained from Applied Biosystems assays-ondemand (ID nos. Hs00823638, Hs00231653, Hs00174128, Hs00174103, 4333762F, respectively). PCR was conducted using the following cycle parameters: $95^{\circ} \mathrm{C}, 12 \mathrm{~min}$ for $1 \mathrm{cycle}\left(95^{\circ} \mathrm{C}, 20 \mathrm{~s} ; 60^{\circ} \mathrm{C}, 1 \mathrm{~min}\right)$, for 40 cycles. Analysis was conducted using the sequence detection software supplied with the ABI 7300. The software calculates the threshold cycle $\left(C_{t}\right)$ for each reaction, and this was used to quantify the amount of starting template in the reaction. The $C_{t}$ values for each set of duplicate reactions were averaged for all subsequent calculations. A difference in $C_{t}$ values $\left(\Delta C_{t}\right)$ was calculated for each gene by taking the mean $C_{t}$ of each gene of interest and subtracting the mean $C_{t}$ for $\beta$-actin for each cDNA sample. Assuming that each reaction functions at 100\% PCR efficiency, a difference of one $C_{t}$ represents a fourfold difference. Relative expression levels were expressed as a fold increase in mRNA expression and

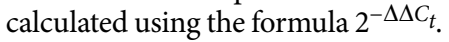

Assessment of secreted antibacterial activity by ECC-1 cells and polarized primary uterine epithelial cells in culture. The effect of epithelial cell rinses derived from cell insert monolayer cultures on bacterial viability has been described. ${ }^{11}$ ECC-1 cells were grown to maximal TER and treated with or without $1 \times 10^{-8}$ or $1 \times 10^{-9} \mathrm{M} \mathrm{E}_{2}$ in the basolateral chamber for $24 \mathrm{~h}$. The media in the apical and basolateral chambers were without FBS and antibiotics. Following incubation, media were centrifuged at $10,000 \mathrm{~g}$ and supernatants were incubated with either $S$. aureus or N. gonorrhoeae for $1 \mathrm{~h}$, and finally, using a bacteria spreader, cultured on bacterial plates for $24 \mathrm{~h}$ and colony-forming units (CFUs) were enumerated. CM from cell inserts without cells were used as controls.

Statistics. The data from ELISA assays are presented as the mean \pm standard error of the mean. InSTAT Software was used to perform a one-way repeated-measures analysis of variance. When an analysis of variance indicated that significant differences existed among means, preplanned paired comparisons were made using the Dunnet method to adjust $P$-values. A $P$-value of less than 0.05 was taken as indicative of statistical significance.

\section{ACKNOWLEDGMENTS}

We thank Vincent Memoli, MD, Section Chief of Anatomical Pathology, for procuring tissues; other members of the Department of Pathology for inspecting and dissecting tissue specimens: Jorge Gonzalez, Alan Schned, Vincent Memoli, Peter Seery, Shannon Schutz, Elizabeth Rizzo, Richard Merrill, Charles-Robert Moultry, Patricia Larkin, Aimee Larson, Jennifer Simonton, Emily Kimball, Christopher Sylvest, and Dawn Maddaline; for clinical support and scheduling: Karen Carter, Linda Hallock, Tamara Krivit, Joanne Lavin, Kathleen Pilchman, Kris Ramsey, and Laura Wolfe; surgeons: Barry Smith, Steven Andrews, Emily Baker, Joan Barthold, Jackson Beecham, Deb Birenbaum, John Currie, Leslie
Demars, Tina Foster, Karen George, Paul Hanissian, Dianne Harper, Nancy Kennedy, John Ketterer, Michele Lauria, Benjamin Mahlab, Paul Manganiello, Judith McBean, Misty Porter, Eric Sailer, Kris Strohbehn, Stanley Stys, James Whiteside, Roger Young, William Young; OR Nurses: Jaclyn Logan, Fran Reinfrank, Jeanette Sawyer, and Tracy Stokes. This work was supported by NIH grants Al-51877 and Al-13541.

\section{DISCLOSURE}

The authors declared no conflict of interest.

() 2008 Society for Mucosal Immunology

\section{REFERENCES}

1. Wira, C.R. \& Fahey, J.V. The innate immune system: gatekeeper to the female reproductive tract. Immunology 111, 13-15 (2004).

2. Wira, C.R., Fahey, J.V., Sentman, C.L., Pioli, P.A. \& Shen, L. Innate and adaptive immunity in female genital tract: cellular responses and interactions. Immunol. Rev. 206, 306-335 (2005).

3. Wira, C.R., Grant-Tschudy, K.S. \& Crane-Godreau, M.A. Epithelial cells in the female reproductive tract: a central role as sentinels of immune protection. Am. J. Reprod. Immunol. 53, 65-76 (2005).

4. Medzhitov, R.M. \& Janeway, C.J. Innate immunity. N. Engl. J. Med. 343, 338-344 (2000).

5. Schaefer, T.M., Desouza, K., Fahey, J.V., Beagley, K.W. \& Wira, C.R. Toll-like receptor (TLR) expression and TLR-mediated cytokine/ chemokine production by human uterine epithelial cells. Immunology 112, 428-436 (2004).

6. Fahey, J.V., Schaefer, T.M., Channon, J.Y. \& Wira, C.R. Secretion of cytokines and chemokines by polarized human epithelial cells from the female reproductive tract. Hum. Reprod. 20, 1439-1446 (2005).

7. Lesmeister, M.J., Jorgenson, R.L., Young, S.L. \& Misfeldt, M.L. 17Betaestradiol suppresses TLR3-induced cytokine and chemokine production in endometrial epithelial cells. Reprod. Biol. Endocrinol. 3, 74 (2005).

8. Crane-Godreau, M.A. \& Wira, C.R. Effects of estradiol on lipopolysaccharide and Pam3Cys stimulation of CCL20/macrophage inflammatory protein 3 alpha and tumor necrosis factor alpha production by uterine epithelial cells in culture. Infect. Immun. 73, 4231-4237 (2005).

9. Yang, D. et al. Many chemokines including CCL20/MIP-3alpha display antimicrobial activity. J. Leukoc. Biol. 74, 448-455 (2003).

10. Yang, D. et al. Beta-defensins: linking innate and adaptive immunity through dendritic and T cell CCR6. Science 286, 525-528 (1999).

11. Fahey, J.V. \& Wira, C.R. Effect of menstrual status on antibacterial activity and secretory leukocyte protease inhibitor production by human uterine epithelial cells in culture. J. Infect. Dis. 185, 1606-1613 (2002).

12. Ganz, T. Defensins: antimicrobial peptides of innate immunity. Nat. Rev. Immunol. 3, 710-720 (2003).

13. Quayle, A.J. et al. Gene expression, immunolocalization, and secretion of human defensin-5 in human female reproductive tract. Am. J. Pathol. 152, 1247-1258 (1998).

14. Duits, L.A. et al. Rhinovirus increases human beta-defensin-2 and -3 mRNA expression in cultured bronchial epithelial cells. FEMS Immunol. Med. Microbiol. 38, 59-64 (2003).

15. Ganz, T. Defensins and host defense. Science 286, 420-421 (1999).

16. Hiemstra, P.S. et al. Antibacterial activity of antileukoprotease. Infect. Immun. 64, 4520-4524 (1996).

17. Hocini, H. et al. Secretory leukocyte protease inhibitor inhibits infection of monocytes and lymphocytes with human immunodeficiency virus type 1 but does not interfere with transcytosis of cell-associated virus across tight epithelial barriers. Clin. Diagn. Lab. Immunol. 7, 515-518 (2000).

18. Lehrer, R.I. \& Ganz, T. Defensins of vertebrate animals. Curr. Opin. Immunol. 14, 96-102 (2002).

19. McNeely, T. et al. Inhibition of human immunodeficiency virus type 1 infectivity by secretory leukocyte protease inhibitor occurs prior to viral reverse transcription. Blood 90, 1141-1149 (1997).

20. Porter, E. et al. Distinct defensin profiles in Neisseria gonorrhoeae and Chlamydia trachomatis urethritis reveal novel epithelial cell-neutrophil interactions. Infect. Immun. 73, 4823-4833 (2005)

21. Quinones-Mateu, M.E. et al. Human epithelial beta-defensins 2 and 3 inhibit HIV-1 replication. AIDS 17, F39-F48 (2003).

22. Shugars, D. Endogenous mucosal antiviral factors of the oral cavity. J. Infect. Dis. 179 (Suppl. 3), S431-S435 (1999). 
23. Tomee, J.F., Hiemstra, P.S., Heinzel-Wieland, R. \& Kauffman, H.F. Antileukoprotease: an endogenous protein in the innate mucosal defense against fungi. J. Infect. Dis. 176, 740-747 (1997).

24. Correale, J., Arias, M. \& Gilmore, W. Steroid hormone regulation of cytokine secretion by proteolipid protein-specific CD4+ T cell clones isolated from multiple sclerosis patients and normal control subjects. J. Immunol. 161, 3365-3374 (1998).

25. Beato, M., Chalepakis, G., Schauer, M. \& Slater, E.P. DNA regulatory elements for steroid hormones. J. Steroid. Biochem. 32, 737-747 (1989).

26. Paech, K. et al. Differential ligand activation of estrogen receptors ERalpha and ERbeta at AP1 sites. Science 277, 1508-1510 (1997).

27. Denison, F.C., Kelly, R.W., Calder, A.A. \& Riley, S.C. Secretory leukocyte protease inhibitor concentration increases in amniotic fluid with the onset of labour in women: characterization of sites of release within the uterus. J. Endocrinol. 161, 299-306 (1999).

28. King, A.E., Critchley, H.O. \& Kelly, R.W. Presence of secretory leukocyte protease inhibitor in human endometrium and first trimester decidua suggests an antibacterial protective role. Mol. Hum. Reprod. 6, 191-196 (2000).

29. King, A.E., Fleming, D.C., Critchley, H.O. \& Kelly, R.W. Differential expression of the natural antimicrobials, beta-defensins 3 and 4 , in human endometrium. J. Reprod. Immunol. 59, 1-16 (2003).

30. King, A.E., Morgan, K., Sallenave, J.M. \& Kelly, R.W. Differential regulation of secretory leukocyte protease inhibitor and elafin by progesterone. Biochem. Biophys. Res. Commun. 310, 594-599 (2003).

31. Keller, M.J. et al. PRO 2000 elicits a decline in genital tract immune mediators without compromising intrinsic antimicrobial activity. AIDS 21, 467-476 (2007).

32. Schumacher, G.F.B. Soluble proteins in cervical mucus In The Biology of the Cervix (Blandau, R.J. \& Moghissi, K., eds) 201-233 (The University of Chicago Press: Chicago, IL, 1973).

33. Beagley, K.W. \& Gockel, C.M. Regulation of innate and adaptive immunity by the female sex hormones oestradiol and progesterone. EFEMS Immunol. Med. Microbiol. 38, 13-22 (2003).

34. Kanda, N. \& Watanabe, S. 17 beta-estradiol inhibits the production of interferon-induced protein of $10 \mathrm{kDa}$ by human keratinocytes. J. Invest. Dermatol. 120, 411-419 (2003).

35. Kanda, N. \& Watanabe, S. 17beta-estradiol inhibits the production of RANTES in human keratinocytes. J. Invest. Dermatol. 120, 420-427 (2003).

36. Kanda, N. \& Watanabe, S. 17Beta-estradiol inhibits MCP-1 production in human keratinocytes. J. Invest. Dermatol. 120, 1058-1066 (2003).

37. Wakeling, A.E., Dukes, M. \& Bowler, J. A potent specific pure antiestrogen with clinical potential. Cancer Res. 51, 3867-3873 (1991).

38. Schaefer, T.M., Fahey, J.V., Wright, J.A. \& Wira, C.R. Innate immunity in the human female reproductive tract: antiviral response of uterine epithelial cells to the TLR3 agonist poly(I:C). J. Immunol. 174, 992-1002 (2005).

39. Schaefer, T.M., Fahey, J.V., Wright, J.A. \& Wira, C.R. Migration inhibitory factor secretion by polarized uterine epithelial cells is enhanced in response to the TLR3 agonist poly (I:C). Am. J. Reprod. Immunol. 54, 193-202 (2005).

40. Dinarello, C.A. Interleukin 1 and interleukin 18 as mediators of inflammation and the aging process. Am. J. Clin. Nutr. 83, 447S-455S (2006).

41. Schaefer, T.M., Wright, J.A., Pioli, P.A. \& Wira, C.R. IL-1beta-mediated proinflammatory responses are inhibited by estradiol via down-regulation of IL-1 receptor type I in uterine epithelial cells. J. Immunol. 175, 6509-6516 (2005).

42. Shugars, D.C., Sauls, D.L. \& Weinberg, J.B. Secretory leukocyte protease inhibitor blocks infectivity of primary monocytes and mononuclear cells with both monocytotropic and lymphocytotropic strains of human immunodeficiency virus type I. Oral Dis. 3 (Suppl 1), S70-S72 (1997).

43. Shimoya, K. et al. Secretory leukocyte protease inhibitor levels in cervicovaginal secretion of elderly women. Maturitas 54, 141-148 (2006).

44. Kunz, G. et al. The uterine peristaltic pump. Normal and impeded sperm transport within the female genital tract. Adv. Exp. Med. Biol. 424, 267-277 (1997).

45. Parsons, A.K., Cone, R.A. \& Moench, T.R. Uterine uptake of vaginal fluids; implications or microbicides. Presented at Microbicides 2002, Antwerp Belgium. Abst \#B-175, page 36 (2002).

46. Lentsch, A.B., Yoshidome, H., Warner, R.L., Ward, P.A. \& Edwards, M.J. Secretory leukocyte protease inhibitor in mice regulates local and remote organ inflammatory injury induced by hepatic ischemia/reperfusion. Gastroenterology 117, 953-961 (1999).

47. Lentsch, A.B. et al. Inhibition of NF- $\kappa$ B activation and augmentation of IkappaBbeta by secretory leukocyte protease inhibitor during lung inflammation. Am. J. Pathol. 154, 239-247 (1999).

48. Ward, P.A. \& Lentsch, A.B. Endogenous regulation of the acute inflammatory response. Mol. Cell Biochem. 234, 225-228 (2002).

49. Nakamura, A. et al. Increased susceptibility to LPS-induced endotoxin shock in secretory leukoprotease inhibitor (SLPI)-deficient mice. J. Exp. Med. 197, 669-674 (2003).

50. Greene, C.M., McElvaney, N.G., O'Neill, S.J. \& Taggart, C.C. Secretory leucoprotease inhibitor impairs Toll-like receptor 2- and 4-mediated responses in monocytic cells. Infect. Immun. 72, 3684-3687 (2004).

51. Taggart, C.C. et al. Secretory leucoprotease inhibitor binds to NF-kappaB binding sites in monocytes and inhibits p65 binding. J. Exp. Med. 202, 1659-1668 (2005).

52. Lee, Y.W., Eum, S.Y., Nath, A. \& Toborek, M. Estrogen-mediated protection against HIV Tat protein-induced inflammatory pathways in human vascular endothelial cells. Cardiovasc. Res. 63, 139-148 (2004).

53. Gruber, C.J., Tschugguel, W., Schneeberger, C. \& Huber, J.C. Production and actions of estrogens. N. Engl. J. Med. 346, 340-352 (2002).

54. Kian Tee, M. et al. Estradiol and selective estrogen receptor modulators differentially regulate target genes with estrogen receptors alpha and beta. Mol. Biol. Cell 15, 1262-1272 (2004).

55. Wallace, P.K. et al. MHC class II expression and antigen presentation by human endometrial cells. J. Steroid Biochem. Mol. Biol. 76, 203-211 (2001).

56. Yeaman, G.R. et al. Chemokine receptor expression in the human ectocervix: implications for infection by the human immunodeficiency virus-type I. Immunology 113, 524-533 (2004).

57. Grant-Tschudy, K.S. \& Wira, C.R. Effect of estradiol on mouse uterine epithelial cell transepithelial resistance (TER). Am. J. Reprod. Immunol. 52, 252-262 (2004).

58. Mo, B. et al. ECC-1 cells: a well-differentiated steroid-responsive endometrial cell line with characteristics of luminal epithelium. Biol. Reprod. 75, 387-394 (2006).

59. Godfrey, T.E. et al. Quantitative mRNA expression analysis from formalin-fixed, paraffin-embedded tissues using $5^{\prime}$ nuclease quantitative reverse transcription-polymerase chain reaction. J. Mol. Diagn. 2, 84-91 (2000). 